\title{
The Use of Soil Palynomorphs in Forensics
}

\author{
${ }^{* 1}$ ABDULRAHAMAN, AA; ${ }^{2}$ AL SAHLI, AA; ${ }^{1}$ OKOLI, JU \\ ${ }^{1}$ Applied Plant Anatomy and Wood Technology Laboratory, Department of Plant Biology, University of Ilorin, Ilorin, Nigeria \\ ${ }^{2}$ Department of Botany and Microbiology, College of Science, King Saud University, Riyadh, Saudi Arabia \\ *Corresponding Authors: abdulrahamanaa@Unilorin.Edu.Ng; +2348033897870
}

\begin{abstract}
The aim was to establish the forensic value of using palynomorphs in soil samples to link people or objects to crime scenes in order to establish or strengthen an association. This was done by determining the degree to which pollen assemblages of surface soil samples differ within the same area. Samples within the same localized area (the control site) showed a high degree of similarity, suggesting that pollen assemblages of surface soil samples from within a localized area are homogeneous. Standard methods were used for the collection and analysis of soil samples such as deflocculation, acetolysis for removal of cellulose and organic matter and silicate removal method to achieve better visualization and identification of pollen types. The results indicated that the cast of footprints and palm prints provided evidence of a two way transfer of materials between the palms and feet and the soil of the grassy area. Pollen analysis of the soil that had adhered to the palms and feet showed that the perpetrator of the imprint had been standing in that grassy area. The analysis of the interface between the body parts (palms and feet) and soil is therefore a potentially lucrative source of information for forensic reconstruction. This analysis shows that pollen can be used to associate perpetrators to crime scenes and should be seen as a useful tool in the analysis of hitherto unrecognized forensic materials in forensic palynology.
\end{abstract}

\section{DOI: https://dx.doi.org/10.4314/jasem.v22i1.15}

Copyright: Copyright (C) 2017 Abdulraman et al. This is an open access article distributed under the Creative Commons Attribution License (CCL), which permits unrestricted use, distribution, and reproduction in any medium, provided the original work is properly cited

Dates: Received 04 July 2017, received in revised form 23 November 2017, accepted 30 December 2017.

Keywords: Feet, forensics, palms, palynology, palynomorphs, soil

Palynology is the science that studies, contemporary and fossil palynomorphs, including pollen, spores, orbicules, dinoflagellate cysts, acritarchs, chitinozoans and scolecodonts, together with particulate organic matter found in sedimentary rocks and sediments (Jansonius and McGregor, 1996). The study of pollen is called palynology and is highly useful in paleoecology, paleontology, archeology, and forensics. The usefulness of palynomorphs is due to their abundance, dispersal mechanisms, resistance to mechanical and chemical destruction, microscopic size and morphology. Their often complex morphology allows identification to an individual parent plant taxon, which can be related to a specific ecological habitat or a specific scene (Mildenhall et al, 2006). The main forensic application of palynology is to provide associative evidence, i.e. to establish or disprove links among people, places, and objects (Horrocks and Walsh, 1998). If one knows the composition of the pollen grain for a given area, then one will know what pollen assemblage should be found in samples collected from that area (Bryant et al., 1990). Pollen and spores are found everywhere. They are found in glacier ice, in the air, over the poles and over the ocean. It has been said that they have probably a wider distribution with regard to time and space than any other organism (Bryant et al., 1990).

Forensic palynology is the study of pollen and powdered minerals, their identification, and where and when they occur, to ascertain that a body or other object was in a certain place at a certain time. Pollen can tell a lot about where a person or object has been, because regions of the world, or even more particular locations such as a certain set of bushes, will have a distinctive collection of pollens. Pollen evidence can also reveal the season in which a particular object picked up the pollen. Its main forensic application is in providing associative evidence, i.e., assisting to prove or disprove a link between people and objects with places or with other people. For example, soil on a suspect's shoe or clothing can be analyzed for pollen and compared with control soil samples from the crime scene (Chambers, 1998).

Recently solved criminal cases show that the forensic use of pollen and spores can be used in many different crimes. A short list of these cases shows many ways pollen is now being used in the courtroom namely forgery, production and distribution of illegal drugs, assaults, robbery, rapes, homicide, genocide, terrorism, arson, hit and run crimes, counterfeiting of currency, identifying the origin of fake prescription drugs such as Viagra (Mildenhall et al,. 2006).

However, forensic palynology has not made much headway in Nigeria because of the difficulties and problems that are encountered in their isolation and identification (Sowunmi, 1973). The current study, therefore, is to elucidate the degree to which pollen assemblages of surface soil samples from within the 
same localized area differ, and to determine the degree to which the pollen assemblage of a surface soil sample from within a localized area differs from those of other localized areas of similar vegetation type.

\section{MATERIALS AND METHODS}

Collection of samples: An open grassy area, measuring approximately 15 x 6 meters, was selected at a farmland beside the Asa River along Unity Road in Ilorin, Kwara State, North Central Nigeria, which is located between latitude and longitude $8^{\circ} 28^{\prime} 0^{\prime \prime} \mathrm{N}$ to $4^{\circ} 33^{\prime} 0^{\prime} \mathrm{E}$. It forms a hollow approximately 2 meters below surrounding terrain and is surrounded by grasses and scattered shrubs and crops. Soil samples were collected on the $17^{\text {th }}$ of February 2013.

A pair of clean feet and palms which is disinfected using 70\% ethanol was walked once back and forth along the same line of travel (approximately 3.5m) across a muddy part of the grassy area. The resulting tracks consisted of ten pairs of footprints and palm prints, with pair member side by side and $2 \mathrm{~cm}$ to $5 \mathrm{~cm}$ apart. Each member of a pair was made in an opposite direction to the other. From the heel of each footprint and palm print, a soil sample (1mm surface scrapping) was taken with a sterilized scalpel blade. Further samples were taken from each footprint and palm print. The first of these consisted of a $1 \mathrm{~mm}$ surface scraping, the second a gouge was made with the thumb and forefinger in the same place to a depth of approximately $20 \mathrm{~mm}$. The deeper samples were taken to determine whether or not pollen assemblages in surface samples change significantly within this depth. A total of nine samples was collected for analysis (Table 1). Each sample was collected using sterilized polyethylene bags.

Table 1: Sample collection and labelling

\begin{tabular}{lc}
\hline \multicolumn{1}{c}{ Study sample } & Sample number \\
\hline Right palm print & 1 \\
Left palm print & 2 \\
Right palm & 3 \\
Left palm & 4 \\
Right foot print & 5 \\
Left foot print & 6 \\
Left foot & 7 \\
Right foot & 8 \\
20mm soil depth & 9 \\
\hline
\end{tabular}

Isolation and analysis of pollens from soil: The soil samples were oven dried at $105^{\circ} \mathrm{C}$ for 20 minutes soon after collection to inhibit any possible microbial activity. The soil samples were then ground in a mortar and passed through a $1 \mathrm{~mm}$ sieve to remove coarse particles.

The method of Erdtman (1969) was adopted with little modification. One gram of soil of all samples was weighed and poured into different labelled beakers. Digestion was done by adding $10 \% \mathrm{NaOH}$ to each of the tubes. Then the heat $\left(80^{\circ} \mathrm{C}-90^{\circ} \mathrm{C}\right.$ for 2 to
3 minutes) was applied until there is no longer evidence of humic aggregates. The samples were then poured into labelled test tubes to allow for separation of residue from solvent. The separation is done by allowing the solvent settle over a period of time and the supernatant is decanted. The samples are then washed and centrifuged (1000ppm) several times to remove all caustic soda. Washing is done by adding water to the samples, centrifuging and then decanting the supernatant. The samples are then ready for hydrofluoric acid treatment.

A small amount of distilled water was added to the residue and mix thoroughly, and approximately $10 \mathrm{ml}$ of $40 \%$ hydrofluoric acid (HF) was added to centrifuge tube and place in a beaker of boiling water in water bath for about 30 minutes. The content was then centrifuged at $1000 \mathrm{ppm}$ and carefully decant into the labelled collector vessel and not down sinks. Dilute $\mathrm{HCl}$ was added, mixed and put in a simmering water bath for 3-5 minutes (this removes colloidal silica etc.). It was centrifuged again and decant. Lastly, distilled water was added, mixed, centrifuged and decant (Faegri and Iversen, 1989).

A small drop of the soil sample was smeared on a clean slide using a rod. A small drop of isopropyl (isopropanol) was added to the smear and mounted in glycerine. A cover slip was placed over the slide and the edges were permanent with nail polish. Observations were made using light microscope.

Determination of pollen frequency: The frequency of each pollen type was expressed as the percentage occurrence of all pollen types based on all occurrences using the formula:

$P$

$\frac{P}{Y} \times 100$

Where: $\mathrm{P}=$ the occurrence of each pollen type in the field of view, and

$\mathrm{Y}=$ total occurrence of all pollen types per sample.

Statistical analysis: All data were reported and analyzed using analysis of variance (ANOVA) and Duncan's Multiple Range Test (DMRT). Computer software was used. A probability value 0.05 was used as benchmark for significant difference between parameters.

\section{RESULTS AND DISCUSSION}

The descriptive microphotography of the pollen and spore types is compiled in Fig. 1. A total of 8 pollen types was discovered in all samples (Table 2; Fig. 1). The most frequent pollens are those of Sida acuta occurring in all the nine samples while those of Tacca leontopetaloides and Terminalia catappa occurred in only one sample each (Table 3 ). This gives credence to the high occurrence of pollens from the family Malvaceae and lower pollens from the families Dioscoreaceae and Combretaceae where the above 
species belongs (Table 4). Pollens are morphologically diagnostic as most often they are species specific. The fact that the pollens can be identified to the species level is wholly supported by many researchers on polynomorphs to unravel some evidences in forensics, biostratigraphy, climatology, medicine-alleviation of pollinosis (hay feverallergenic disease), forensic studies, mellisopalynology, plant evolution, taxonomy and environmental restoration activities (Adekanmbi, 2009; Ige, 2009 Adeonipekun and Ige, 2007; Palazzesi et al., 2007; Bayer and Kubitzki, 2003)

Pollen grains in Arecaceae family have less variation exhibited in the pollen morphology. They are mostly rounded, triangular to square, sometimes circular in polar view. Apertures of Combretaceae are triporate. Pollen grains in this family are characteristically echinate in ornamentation. Earlier, Sowunmi (1973) gave a similar morphological description. Sida linfolia, S. acuta and Gossypium hirsutum of Malvaceae share similar echinate characteristics. The echinate nature of the species of Malvaceae was also reported by Perveen and Qaiser (2009). The Fabaceae species, namely Delonix regia, Acacia nilotica and Acacia albida are characteristically panporate and quantity disparity was noted by Sowunmi (1973). Ixora coccinea of family Rubiaceae are bicolpate, panporate, participate. Walker (1976) suggested that elaborate exine sculpturing seems to be associated with entomophily, while pollen grains with smooth surfaces are largely characteristic of anemophilous plants. The slight size disparity is however noted in pollen grains of species of Dioscoreaceae and Euphorbiaceae by some researchers. This may not be unconnected with the fact that the pollen grain size is affected by acetolysis (Faegri and Iverson, 1989) and a few other chemicals used for grain isolation.
In order for palynological evidence to be accepted in a court of law, investigators must establish that correlation between the pollen profile of a forensic sample and its purported area of origin is causal and not merely coincidental. The similarities in sample 3 (right palm), 4 (left palm), 7 (left foot) and 8 (right foot), show that the body parts (palms and feet) had come in contact with the pollens in samples 1 (right hand print), 2 (left hand print), 5 (right foot print), 6 (left foot print) and 9 (20mm soil depth). Similarity and differences observed in the presence of pollens in the soil collected from the same area are an indication of good forensic evidence.

The laboratory of Mark Horrocks and associates at the University of Auckland has undertaken several studies that demonstrate the veracity of pollen evidence. They have shown, for instance, that sample of hash oil originating from the same marijuana crop, but subjected to different common filtering materials will show significantly similar pollen assemblages, a result of which is of great use to law enforcement agencies who often seek to determine a link between illicit drug samples found on different people or at different places (Horrocks and Walsh, 1997).

It may be argued that the pollen assemblage of a particular scene, for example an open grassy area, could be similar to the pollen assemblage of any other similar open grassy area. Horrocks and Walsh (1998) have also shown that this is not the case; while different soil samples collected from within a localized region (up to $15 \mathrm{~m}$ ) show similar pollen assemblages, there were significant differences among soil samples collected from different localized regions of similar vegetation type (up to $1 \mathrm{~km}$ ). This is again a demonstration that pollen evidence is a useful tool in associating suspects and objects with crime scenes.

Table 2: Plant species and pollen types

\begin{tabular}{llll}
\hline \multicolumn{1}{c}{ Species } & \multicolumn{1}{c}{ Common name } & \multicolumn{1}{c}{ Families } & Pollen \\
\hline Elaeis guineensis & African oil palm & Arecaceae & Panporate \\
Terminalia catappa & Bengal almond & Combretaceae & Triporate \\
Tacca leontopetaloides & Polynesian arrow foot & Dioscoreaceae & Monosulcate \\
Excoecaria agallocha & Excoecaria agallocha & Euphorbiaceae & Tricolporate \\
Delonix regia & Flamboyant or flame tree & Fabaceae & Panporate \\
Acacia nilotica & Gum Arabic tree & Fabaceae & Panporate \\
Acacia albida & Apple-ring acacia & Fabaceae & Panporate \\
Sida linifolia & Balai grand & Malvaceae & Bicolpate \\
Sida acuta & Common wireweed & Malvaceae & Triporate and panporate \\
Gossypium hirsutum & Upland cotton & Malvaceae & Pericolpate \\
Ixora coccinea & Flame of the woods or jungle & Rubiaceae & Bicolpate, panporate and \\
& flame & & pericolpate \\
Citrus medica & Citron & Rutaceae & Bicolpate \\
\end{tabular}




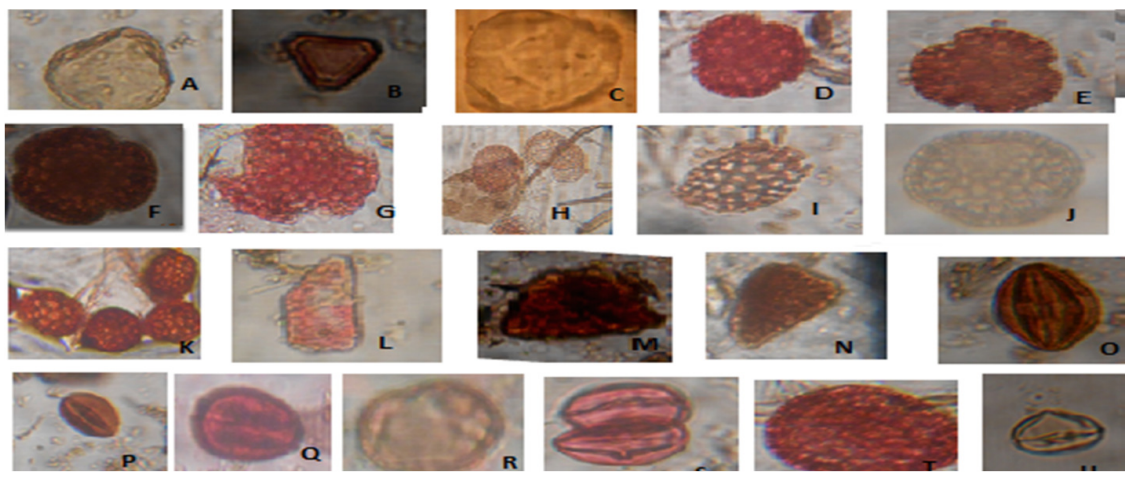

Fig. 1: Pollens recovered from the study site: a - panporate pollen of Elaeis guineensis, $\mathrm{b}$ - triporate pollen of Terminalia catappa, $\mathrm{c}$ - monosulcate pollen of Tacca leontopetaloides, d, e, $\mathrm{f}$ tricolporate pollens of Excoecaria agallocha, $\mathrm{g}$ - panporate pollen of Acacia albida, h, i - panporate pollens of Acacia nolitica, $\mathrm{j}, \mathrm{k}$ - panporate pollen of Delonix regia, 1 - triporate pollen of Sida acuta, $\mathrm{m}, \mathrm{n}$ - panporate pollens of Sida acuta, $\mathrm{o}, \mathrm{p}$ - bicolpate pollen of Sida linfolia, $\mathrm{q}$ - pericolpate pollen of Gossypium hirsutum, $\mathrm{r}$ - pericolpate pollen of Ixora coccinea, $\mathrm{s}$ - bicolpate pollen of

\begin{tabular}{|c|c|c|c|c|}
\hline Study samples & Total pollen per species & Frequency $(\%)$ & Species & Family \\
\hline \multirow[t]{6}{*}{ Right palm print } & 22 & 10.58 & Citrus medica & Rutaceae \\
\hline & 24 & 11.53 & Delonix regia & Fabaceae \\
\hline & 51 & 24.51 & Ixora coccinea & Rubiaceae \\
\hline & 17 & 8.17 & Tacca leontopetaloides & Dioscoreaceae \\
\hline & 39 & 18.75 & Sida linfolia & Malvaceae \\
\hline & 55 & 26.44 & Sida acuta & Malvaceae \\
\hline \multirow[t]{5}{*}{ Left palm print } & 40 & 42.10 & Ixora coccinea & Rubiaceae \\
\hline & 32 & 33.68 & Sida acuta & Malvaceae \\
\hline & 12 & 12.63 & Acacia nilotica & Fabaceae \\
\hline & 11 & 11.57 & Excoecaria agallocha & Euphorbiaceae \\
\hline & 14 & 11.20 & Citrus medica & Rutaceae \\
\hline \multirow[t]{6}{*}{ Right palm } & 8 & 6.40 & Delonix regia & Fabaceae \\
\hline & 13 & 10.40 & Acacia nilotica & Fabaceae \\
\hline & 37 & 29.60 & Ixora coccinea & Rubiaceae \\
\hline & 22 & 17.6 & Sida linfolia & Malvaceae \\
\hline & 31 & 24.80 & Sida acuta & Malvaceae \\
\hline & 11 & 12.08 & Gossypium hirsutum & Malvaceae \\
\hline \multirow[t]{3}{*}{ Left palm } & 40 & 43.95 & Ixora coccinea & Rubiaceae \\
\hline & 23 & 25.27 & Sida acuta & Malvaceae \\
\hline & 17 & 18.68 & Sida linfolia & Malvaceae \\
\hline \multirow[t]{5}{*}{ Right foot print } & 8 & 6.10 & Elaeis guineensis & Arecaceae \\
\hline & 52 & 39.69 & Ixora coccinea & Rubiaceae \\
\hline & 45 & 34.35 & Sida acuta & Malvaceae \\
\hline & 16 & 12.21 & Delonix regia & Fabaceae \\
\hline & 10 & 7.63 & Excoecaria agallocha & Euphorbiaceae \\
\hline \multirow{5}{*}{ Left foot print } & 9 & 11.25 & Delonix regia & Fabaceae \\
\hline & 24 & 30.00 & Ixora coccinea & Rubiaceae \\
\hline & 31 & 38.75 & Sida acuta & Malvaceae \\
\hline & 8 & 10.00 & Terminalia catappa & Combretaceae \\
\hline & 8 & 10.00 & Excoecaria agallocha & Euphorbiaceae \\
\hline \multirow[t]{6}{*}{ Left foot } & 11 & 13.09 & Acacia albida & Fabaceae \\
\hline & 6 & 7.50 & Gossypium hirsutum & Malvaceae \\
\hline & 28 & 33.33 & Ixora coccinea & Rubiaceae \\
\hline & 14 & 16.66 & Sida linfolia & Malvaceae \\
\hline & 19 & 22.61 & Sida acuta & Malvaceae \\
\hline & 6 & 7.14 & Delonix regia & Fabaceae \\
\hline \multirow[t]{4}{*}{ Right foot } & 8 & 10.66 & Elaeis guineensis & Arecaceae \\
\hline & 22 & 29.33 & Ixora coccinea & Rubiaceae \\
\hline & 27 & 36.00 & Sida linfolia & Malvaceae \\
\hline & 18 & 24.00 & Sida acuta & Malvaceae \\
\hline \multirow[t]{2}{*}{$20 \mathrm{~mm}$ depth } & 18 & 46.15 & Ixora coccinea & Rubiaceae \\
\hline & 21 & 53.85 & Sida acuta & Malvaceae \\
\hline
\end{tabular}

Table 4: Frequency of pollens per plant family

\begin{tabular}{|c|c|c|}
\hline Families & Pollen & Frequency $(\%)$ \\
\hline Arecaceae & 31 & 2.12 \\
\hline Combretaceae & 25 & 1.73 \\
\hline Dioscoreaceae & 18 & 1.23 \\
\hline Euphorbiaceae & 143 & 9.78 \\
\hline Fabaceae & 308 & 21.06 \\
\hline Malvaceae & 527 & 36.04 \\
\hline Rubiaceae & 361 & 24.69 \\
\hline Rutaceae & 49 & 3.35 \\
\hline Total & 1462 & 100 \\
\hline
\end{tabular}

Conclusion: Results from this study suggest that pollen assemblages of surface soil samples from within the same localized area are homogeneous. This illustrates that pollen analysis of soil samples is a valuable forensic tool in associating suspects and objects with crime scenes.
Acknowledgement: The authors extend their appreciation to the Deanship of Scientific Research at King Saud University for funding this work through Research Group No.: RG-1438 - 036.

\section{REFERENCES}

Adekanmbi, OH (2009). Pollen grains of Asteraceae and analogous echinate grains. International Journal of Botany, 5: 295-300.

Adeonipekun, AP; Ige, EO (2007). The refugia forest phenomenon: Implications on the palaepalynology of the Neogene Niger/Cross River Delta. Science Focus, 12: 17-21.

Bayer, C; Kubitzki, K (2003). Malvaceae. In: The Families and Genera of Vascular Plants, Kubitzki, K (Ed.). Vol. 5. Capparales and Non- 
Betalain Caryophyllales, Malvales, Springer, Berlin. pp. 225-311.

Bryant, VM Jr; Mildenhall, DC; Jones, JG (1990). Forensic Palynology in the United States of America, 14: 193-208.

Chambers, FM (1998). The Palynological Investigations. In: Fasham, P.J., Kelly, R.S., Mason, MA; White, RB (eds) (1998). The Graeanog Ridge: the Evolution of a Farming Landscape and its Settlements in North-West Wales. Cambrian Archaeological Monographs, No. 6. Cambrian Archaeological Association, Aberystwyth, 52-63.

Erdtman, G (1969). Handbook of Palynology. Munksgaard, Copenhagen. pp. 486.

Faegri, K; Iversen, J (1989). Textbook of Pollen Analysis, 4th Edition. Wiley and Sons, Inc. Chichester, New York. pp. 328.

Horrocks, M; Walsh, KAJ (1998). Forensic palynology: assessing the value of the evidence, V.A. (Eds) Review of Paleobotany and Palynology, Special Issue, New Frontiers and Applications in Palynology- IX IPC.103, 69-74.
Horrocks, M; Walsh, KAJ (1997). A Bayesian approach to interpreting forensic pollen evidence. Review of Paleobotany and Palynology, pp. 947.

Ige, OE (2009). A late tertiary pollen record from Niger Delta, Nigeria. Int. J. Bot., 5: 203-215.

Jansonius, J; McGregor, DC (1996). Introduction, Palynology: Principles and pplications. American Association of Stratigraphic Palynologists Foundation, 1: 1 - 10.

Mildenhall, DC; Wiltshire, PE; Bryant, VM Jr (2006). Hypericum pollen determines the presence of burglars at the scene of a crime: An example of forensic palynology. Forensic Science International, 163(3): 231-235.

Palazzesi, L; Pujana, RR; Burrieza, HP; Steinhardt, AP (2007). Pollen grain morphology of selected allergenic species native to Southern South America. J. Torrey Botanic. Soc., 134: 527-533.

Perveen, A; Qaiser, M (2009). Pollen flora of Pakistan-Malvaceae: Dombeyoideae-Lxii. Pak. J. Bot., 41: 491-494.

Sowunmi, MA (1973). Pollen grains of Nigeria plants 1. Woody species. Grana, 13: 145-186. 